taken by the Ministry of Health. It is reasonable to insist on the compulsory treatment of those who are proved centres of contagion, and it is right that instruction should be given in how to avoid venereal disease, provided such instruction is always accompanied by the statement that there is no safety except in the avoidance of promiscuity. More propaganda is needed to bring home to all both the personal and social dangers incurred by promiscuity, and the vital importance of early treatment if the disease is contracted. Special care should be taken to provide recreation for all isolated camps. Many more women police are required to deal with silly and thoughtless girls who hang about the camps pestering the men and who pay no heed to the remonstrances of voluntary workers.

Our own immediate duty as Church people is to see that our Moral Welfare Work does not lack funds to carry on its essential work; and that individual Christians bear their witness fearlessly and intelligently in upholding the Christian standard. In doing this we must not fall into the error, too often made in the past, of treating sexual wrongdoing as the great sin. Christian morality always regards pride as the sin which above all others separates man from God and his neighbour. If we bear this in mind we shall be the less likely to adopt a superior or rigid attitude to those who have yielded to the sins of flesh. When we condemn the sin, we must not forget to point the way to repentance. And when we exhort men and women to resist this temptation we must not forget to tell them that God is ready to strengthen our weak wills. I have felt it right to speak plainly for we are often accused of refusing to face the hard facts. The younger generation discuss sex problems with great freedom, sometimes with greater freedom than knowledge. We shall never be able to help them if we adopt a cowardly policy of silence. Knowledge of the physical facts of sex is insufficient, what is needed is more intelligent teaching of the Christian view of sex if we are to avoid moral chaos.",

\title{
CORRESPONDENCE
}

\section{THE NEW JOURNAL}

Sir,-The members of the M.S.S.V.D. and other readers of your Journal will, I am sure, associate themselves with me in congratulating you and your Editorial colleagues on the March number of the British Journal of Venereal Diseases.

Although a war-time production, it appears to me to show several advantages over its former self and especially in the excellent and varied fare which it provides for our consumption. May it grow from strength to strength so that it will become a potent force in the land by stimulating the interest of the medical profession and of the intelligent layman (including women) in the subject of venereal diseases, an interest which has been aroused and which must not again be allowed to slacken.

One hopes too that the Jourkal in its new form may be the means of stimulating research in venereal diseases which has been rather conspicuously absent in this country. In this connection one would like to offer the suggestion that some workable arrangement be made with the United States Public Health Service whereby you, Sir, might be permitted to use in your Journal any of the material contained in its very valuable publication, Venereal Diseases Information.

I should like to endorse everything you say about Col. L. W. Harrison, for without him this Journal could not have achieved its present sturdy condition.

I was interested, Sir, in the very interesting case of gumma of the tongue in a congenital syphilitic recorded by Dr. Morna Rawlins and yourself. These cases are distinctly rare nowadays, and I saw only one such during an experience of over twenty years. What shocks one, however, is your statement that the absolutely typical Hutchinsonian right incisor tooth does not appear to have been recognized as such by officers of the school medical and dental services, and this thirty years after the institution of these services and ninety years after Hutchinson so carefully described them. Obviously our school medical and dental services need some overhauling so that cases of congenital syphilis will not be missed as this one was.- 1 am, etc., 